\title{
Communication and Mutual Resource Exchange in North Florida Hermit Crabs
}

\author{
Brian A. Hazlett \\ Division of Biological Sciences, University of Michigan, Ann Arbor, Michigan 48109, USA
}

Received February 20, 1979 / Accepted August 31, 1979

Summary. The patterns of shell exchange in three species of hermit crabs which overlap in distribution and shell use were observed in the laboratory. Crabs showed no tendency to initiate more exchanges with conspecifics as compared with nonconspecific individuals and there were no specific size dominance effects. Lack of common communicatory patterns between Clibanarius vittatus and Pagurus pollicaris was correlated with minimal actual exchange, while Pagurus impressus exchanged with both species and executed patterns in common with both. The pattern of shell exchanges and preferences indicated that, in some cases, both individuals may gain in interspecific exchanges.

\section{Introduction}

It seems axiomatic that the ability to communicate in animals is favored in situations where the exchange of information increases individual fitness. Where the information exchange involves the acquisition or distribution of limited resources, two main patterns have been described. Sharing of resource information (and the resources) is common between individuals of the same social unit in social insects (Wilson, 1971). In contrast, resource distribution between nonrelated individuals is usually mediated by agonistic behavior patterns. The adaptive significance of agonistic behavior is that, on the average, the patterns executed result in acquisition or retention of needed resources by the individual showing such behavior.

Since resource utilization between individuals of the same species will almost always overlap more than resource utilization between individuals of different species, it follows that selection for efficient/accurate intraspecific communication (about resource distribution) should be stronger than selection for interspecific communication. Indeed, in some situations it is questioned whether patterns such as interspecific territorial behavior (Orians and Willson, 1964; Rice, 1978) are due to mistakes in species identification (Murray, 1976) or a result of selection for patterns mediating such interactions (Cody, 1974).

The resource distribution system of hermit crabs may be fundamentally different from those of other animals and makes possible, or even probable, selection for functionally different types of communication systems. Hermit crabs, with rare exception, need empty gastropod shells for protection (Reese, 1968, 1969). It is generally agreed that the supply of this resource item is the primary factor limiting population growth in most areas (Bach et al., 1976; Kellogg, 1976; Provenzano, 1960; Spight, 1977; Vance, 1972). As no empty shells were found in the areas surveyed in this study, it was assumed (without additional verification) that shells are limiting at this site. Occupation of inappropriate size or species of shells reduces fitness by effects on fecundity (Bach et al., 1976; Fotheringham, 1976a), growth (Drapkin, 1963; Fotheringham, 1976b; Markham, 1968), and survivorship (Vance, 1972). Hermit crabs show unique behavior patterns which result in shell exchange between individual crabs (Hazlett, 1966, 1970, 1972), further indicating the importance of these resources to these crustaceans. One crab initiates an interaction by getting in an opposed position (Hazlett, 1966) with respect to the noninitiating crab's shell and then executes positioning and rapping movements. The noninitiating crab either stays withdrawn in its shell, comes up in the aperture of its shell and executes visual displays (Hazlett, 1970), or vacates its shell after signaling the initiating crab by light tapping in its chelipeds.

This system has several unusual features. First, the resource item (shell) of each individual is always in very close proximity to the individual-unlike a 
fixed territory, for example. Thus, interacting animals have the potential to acquire accurate information regarding each other's resource. Second, a resource item can be either too big (locomotion becomes energetically wasteful) or too small (reduced predation protection and inhibition of growth) for a given-sized crab. In addition, it can be of a preferred or nonpreferred species of gastropod. The second feature means that an exchange of shells could result in a gain (in shell fit) for both interactants and the first feature means both crabs could have the information needed to determine whether that result would occur.

Analysis of the pattern of shell exchanges within one species of hermit crab (Hazlett, 1978) has shown that mutual gain (measured as reduction in the deviation from preferred shell size) occurs in the majority of interactions that result in shell exchanges. In the majority of cases where the noninitiating crab would receive a shell that increases the deviation from its preferred shell size, no exchange occurs.

In interspecific interactions, mutual gain is possible both in terms of shell size and shell species. The present study attempts to answer two main questions about three species of hermit crab found in northern Florida and elsewhere along the Gulf Coast (Clibanarius vittatus, Pagurus pollicaris, and Pagurus impressus). Can animals which utilize resource items in common communicate about the exchange of those items, interspecifically? And does the pattern of interspecific shell exchange result in mutual gain to the individuals involved?

\section{Materials and Methods}

Collections were made in two locations in the area of the Florida State University Marine Laboratory, Sopchoppy, Florida. These collections provided specimens for laboratory observations and data on the distributions of shell species utilized by each crab species in the field. The locations chosen were known to contain populations of two crab species and are not necessarily indicative of the degree of species overlap in distribution along the northern Florida coast in general. While other sites containing only one species were surveyed in connection with other studies, no systematic area-wide counts were made to determine the frequency of overlap vs monospecific areas.

Two collections were made at Dog Island Shoals, an offshore site in about $2 \mathrm{~m}$ of water, $6 \mathrm{~km}$ offshore and to the east of the Florida State Marine Laboratory. For both collections, a boat was anchored and all hermit crabs in an area of about $300 \mathrm{~m}^{2}$ around the boat were collected. Shell species occupied was recorded for each crab species and the specimens were brought back to the laboratory. The second site was at Bay Mouth Bar, a projection at the mouth of Alligator Harbor, $20 \mathrm{~km}$ to the east of the Marine Laboratory. An intertidal area about $3 \mathrm{~m}$ wide (from the waterline to offshore) and $100 \mathrm{~m}$ long (parallel to shore) was searched and all crabs collected. This size area was chosen since daily movement studies (B.A. Hazlett, in preparation) indicated that individuals of one species (C. vittatus) regularly moved that far every day, and thus could potentially encounter resources (shells) over such an area. The shell species occupied by crabs were recorded and the animals returned to the laboratory.

Observations on shell exchanges were made in the laboratory by placing an equal number (5-8 in a given observation period) of all three species (Clibanarius vittatus, Pagurus pollicaris, and Pagurus impressus) in $45-1$ aquaria $(53 \times 35 \mathrm{~cm}$ bottom) and watching for shell exchange behavior. The sizes of crabs used were very similar in the three species to maximize the possibility of interspecific shell exchanges. Interactions were counted only if rapping behavior (Hazlett, 1966, 1972) occurred, since this behavior is seen only in the context of shell exchanges and necessarily precedes an exchange. For each interaction the number of raps executed was counted, whether or not an exchange of shells occurred, and the species of crabs involved and the species of shell each occupied were recorded. After the interaction was terminated (either by an exchange or by the initiating crab moving away), the interactants were removed from the observation aquarium and new individuals of the appropriate species added to maintain equal numbers of the three crab species. The interactants were removed from their shells, cephalothorax length (c.l.) and sex recorded, and the shells weighed after drying for 3 days at room temperature.

In connection with other experiments, a separate set of individuals of $C$. vittatus was placed in aquaria with a large excess of empty gastropod shells (4-5 empty shells per crab) of the size and species commonly utilized by these crabs. After 3 days of 'free access', the crabs were removed from their shells, size recorded, and the species and weight (after 3 days of drying) of the shells recorded. These data were then used to calculate the relationship between crab size and shell weight 'preferred' by the crabs when given a choice. Subsequently, the preferred shell weight of any given sized individual of $C$. vittatus could be calculated.

\section{Results}

\section{Field Surveys}

A total of 195 crabs were collected at the Bay Mouth Bar (BMB) site and 113 at Dog Island Shoals (DIS). $P$. pollicaris and $C$. vittatus overlapped in spatial distribution at $\mathrm{BMB}$, while $P$. pollicaris and $P$. impressus co-occurred at DIS. As shown in Table 1, a number of shell species were occupied at both sites. While certain shell species were occupied more frequently by particular crab species (e.g., Busycon contrarium by $C$. vittatus, Strombus pugilator by $P$. impressus, Polinices duplicatus by $P$. pollicaris), there was moderate overlap in resource use at both sites. Colwell and Futuyma's (1971) index of niche overlap between species $i$ and $h$ with respect to resource $j$ was used to estimate degree of overlap:

$C_{\mathrm{ib}}^{1}=\frac{1}{2 \log 2} \sum_{\mathrm{j}}\left[I(\mathrm{pij})+I(\mathrm{phj})-I\left(t_{\mathrm{j}}\right)\right]$

where $I($ pij $)=$ pij $\log$ pij and $t_{\mathrm{j}}=$ pij + phj. This ranges in value from 0 for no overlap to 1 for complete overlap. The degree of resource overlap between species was 0.45 (DIS) and 0.48 (BMB). This is quite close to the overlap in diet between $P$. pollicaris and C. vittatus (0.57) calculated by Caine (1975). 
Table 1. Distribution of gastropod shell species occupied by hermit crabs collected at two sites. Numbers represent percentage of shells occupied by each species at each site

\begin{tabular}{|c|c|c|c|c|}
\hline & \multicolumn{2}{|l|}{ Dog Island Shoals } & \multicolumn{2}{|l|}{ Bay Mouth Bar } \\
\hline & P. impressus $(n=48)$ & P. pollicaris $(n=65)$ & P. pollicaris $(n=60)$ & C. vittatus $(n=135)$ \\
\hline Polinices duplicatus & 0 & 35 & 63 & 4 \\
\hline Turbo castanea & 8 & 26 & 0 & 0 \\
\hline Busycon contrarium & 17 & 6 & 7 & 36 \\
\hline Busycon spiratum & 4 & 9 & 12 & 4 \\
\hline Fasciolaria tulipa & 0 & 0 & 0 & 13 \\
\hline Fasciolaria hunteria & 0 & 9 & 3 & 9 \\
\hline Murex pomum & 6 & 9 & 13 & 4 \\
\hline Strombus pugilator & 35 & 0 & 0 & 0 \\
\hline Oliva sp. & 21 & 0 & 0 & 0 \\
\hline Thais haemastoma & 2 & 5 & 0 & 7 \\
\hline Melogena corona & 4 & 0 & 2 & 21 \\
\hline Phalium sp. & 2 & 0 & 0 & 0 \\
\hline
\end{tabular}

The distribution of shell species used by individuals of $P$. pollicaris at the two sites indicates both similar usage patterns and the opportunistic nature of shell use. That is, at DIS there were apparently fewer specimens of crabs in $P$. duplicatus but numbers in Turbo castanea, a species not found at BMB. Live specimens of $T$. castanea were frequently picked up in the DIS area during the crab collections.

\section{Shell Exchanges}

The Behavior Patterns. In every case except one, noted below, the behavior patterns shown by individuals of each species during these interactions were the same in interspecific and intraspecific interactions and were indistinguishable from the patterns shown by individuals from other populations I have observed elsewhere in Florida.

Initiating individuals of $C$. vittatus executed just one type of rapping motion, 'regular diogenid raps' (Hazlett, 1966). The initiator, while holding the other crab's shell with its ambulatory legs, lifts its own shell high, 4-10 $\mathrm{mm}$ away from the other shell, and then rapidly brings it into contact with the other crab's shell. This movement pattern is seen in all species in the family Diogenidae (Hazlett, 1966, 1972) that have been observed. In contrast, initiating individuals of $P$. pollicaris show only 'spasmodic shaking' raps (Hazlett, 1966). These are very short $(2-3 \mathrm{~mm})$, rapid back-and-forth movements of the other crab's (noninitiator) shell by the initiator's ambulatory legs; the initiator's shell is relatively stationary. This pattern is seen in all species in the family Paguridae but is never executed by diogenid crabs (Hazlett, 1966, 1972). The initiating individual of $P$. impressus executed both diogenid raps and spasmodic shaking raps. In addition, an intermediate pattern I have called 'inverse' raps (Hazlett, 1966) occurred. This involves the sudden pulling of the noninitiator's shell toward the initiator's by the initiator. While spasmodic shaking always occurs in bursts of many movements, inverse raps occur singly and the noninitiator's shell is moved a greater distance $(3-4 \mathrm{~mm})$. Unlike diogenid raps, however, the initiator's shell is not moved.

Execution of the patterns just described by crabs initiating a shell exchange interaction was followed by either the noninitiating crab vacating its shell (= exchange effected) or the initiator leaving the area without an exchange occurring. The behavior patterns were similar to those observed in many other species of hermit crabs. One interaction deserves special consideration due to the unusual nature of the outcome. A C. vittatus had initiated an interaction with a $P$. impressus. After the execution of 56 raps, the P. impressus appeared in the aperture of its shell and tapped lightly on the chelipeds of the $C$. vittatus with its own chelipeds. (This is a pattern seen in almost all species of hermits just prior to the noninitiator vacating its shell. The initiator normally then backs away from the aperture slightly and the noninitiator comes out of its shell. There appear to be slight specific differences in the type of tapping which a vacating crab executes, but I have been unable to characterize clearly those differences.) Instead of backing away slightly, the $C$. vittatus continued to execute raps. The $P$. impressus came up in the aperture of its shell again and repeated the light taps, but the $C$. vittatus persisted in rapping. This continued for about $45 \mathrm{~min}$, with long periods of rapping with the $C$. vittatus down in the shell aperture of the P. impressus. Eventually, appendages of the $P$. impressus were removed by the C. vittatus and finally the whole cephalothorax pulled 
Table 2. Shell exchange patterns by sex of initiator and noninitiator, data for all species summed. In each category, the number of interactions which result in an exchange is given first and the number not resulting in an exchange presented second

\begin{tabular}{lllr}
\hline & \multicolumn{2}{l}{ Noninitiator } & \\
\cline { 2 - 4 } & Male & Female & Total \\
\hline Initiator & & & \\
Male & $9: 21$ & $2: 9$ & $11: 30$ \\
Female & $2: 4$ & $0: 1$ & $2: 5$ \\
Total & $11: 25$ & $2: 10$ & $13: 35$ \\
\hline
\end{tabular}

Table 3. Shell exchange patterns by species. Number of interactions resulting in exchange:number of nonexchange interactions

\begin{tabular}{llllr}
\hline \multicolumn{4}{l}{ Noninitiator } & \\
\cline { 2 - 5 } & C. vittatus & P. pollicaris & P. impressus & Total \\
\hline Initiator & & & & \\
C. vittatus & $0: 3$ & $0: 1$ & $4: 3$ & $4: 7$ \\
P. pollicaris & $0: 10$ & $2: 5$ & $2: 2$ & $4: 17$ \\
$P$. impressus & $1: 4$ & $1: 1$ & $3: 6$ & $5: 11$ \\
Total & $1: 17$ & $3: 7$ & $9: 11$ & $13: 35$ \\
\hline
\end{tabular}

out and then the abdomen. Needless to say, the $P$. impressus was dead.

Patterns of Shell Exchange Interactions. A total of 48 interactions were observed. Examination of the patterns of interaction by sex of the individuals (Table 2) indicated no difference in the probability of an exchange occurring by sex of initiator or noninitiator. More interactions were initiated by males ( 41 compared with 7 by females) and more noninitiators were males $(36: 12)$, but males predominated in the populations sampled at this time of year.

In interactions initiated by males, $25 \%$ resulted in a shell exchange as compared with $29 \%$ for femaleinitiated interactions. When the noninitiator was male, $29 \%$ of the interaction resulted in an exchange, while $20 \%$ of the interactions resulted in exchange when the noninitiator was female. Since there were no sexual differences in the pattern of shell exchange, the data were combined in further analysis.

The pattern of species interactions is shown in Table 3. There were no specific differences in the sum of all interactions (exchange + -nonexchange) involving individuals of each species $(C$. vittatus $=29, P$. pollicaris $=31$, and $P$. impressus $=36$ ). There was also no difference in the number of initiators $\left(\chi^{2}=2.50\right.$, $P>0.10$, comparing the observed distribution with an equal distribution for the three species). Similarly,
Table 4. Mean size $\pm S D$ in mm cephalothorax length of initiating and noninitiating crabs by species

\begin{tabular}{lll}
\hline & Initiating & Noninitiating \\
\hline C. vittatus & $18.7 \pm 34.0$ & $16.4 \pm 50.1$ \\
$P$. pollicaris & $15.8 \pm 32.4$ & $14.4 \pm 44.7$ \\
$P$. impressus & $15.0 \pm 32.2$ & $15.4 \pm 30.5$ \\
\hline
\end{tabular}

there was no difference in the number of noninitiators of each species $\left(\chi^{2}=3.72, P>0.10\right)$.

There were no differences between species in the proportions of interactions resulting in exchanges. Overall, $27 \%$ of the interactions resulted in an exchange, while this varied from $36 \%$ for $C$. vittatus initiators to $19 \%$ for $P$. pollicaris initiators $\left(\chi^{2}=0.95\right.$, $P>0.10)$. These extremes were not due to intraspecific interactions, but were primarily due to $C$. vittatus initiators exchanging more frequently with $P$. impressus, and $P$. pollicaris initiators being unable to effect an exchange with $C$. vittatus. Significant differences were evident in the proportion of interactions with exchanges when the species of noninitiator is considered. This ranged from $5 \%$ for $C$. vittatus to $45 \%$ for $P$. impressus (multicell $\chi^{2}=4.67, P<0.05$ ).

The size of the crabs (millimeter cephalothorax length) engaged in shell exchange interactions does not appear to explain the difference in exchange frequencies seen between the species. There were species differences in the mean size of initiators (ANOVA, $f=4.68, P=0.014$ ), primarily due to the larger size of initiating C. vittatus (Table 4). There were no species differences in the size of noninitiating crabs (ANOVA, $f=0.82, P=0.45$ ). More importantly, there were no differences in the size differences (c.l. initiator minus c.l. of noninitiator) of any species combination in the interactions which resulted in exchange compared with interactions which did not result in exchanges (all $t$-test values associated with $P>0.10$ ). For example, when $C$. vittatus initiated interactions with $P$. impressus, the mean size difference was $+2.9 \mathrm{~mm}$ in interactions with exchange and +3.3 in interactions without exchange $(t=0.11, P>0.10)$.

Interestingly, in one case, an initiating $P$. pollicaris elicited an exchange with a $P$. impressus that was $1.1 \mathrm{~mm}$ larger, but the $P$. impressus was in a Polinices shell (which $P$. pollicaris prefers-see next section) and the $P$. pollicaris in a Strombus shell (which $P$. impressus prefers). There was no significant species effect in the average size of initiators which did effect an exchange with individuals of $P$. impressus.

The number of times initiators of a species started interactions with individuals of each of the three species was not significantly different from that 
Table 5. Distribution of types of raps by initiating individuals of $P$. impressus dependent upon the species of the noninitiating crab. Number of raps expected in each cell if raps and species of noninitiator were independent are given in parentheses

\begin{tabular}{llcr}
\hline & \multicolumn{4}{l}{ Species of noninitiating crab } \\
\cline { 2 - 4 } & $P$. impressus & $P$. pollicaris & C. vittatus \\
\hline Diogenid raps & $170(189)$ & $70(35)$ & $93(108)$ \\
Inverse raps & $186(178)$ & $4(34)$ & $122(102)$ \\
Shaking raps & $41(30)$ & $0(5)$ & $12(17)$ \\
\hline
\end{tabular}

expected by chance in all three cases $\left(\chi^{2}\right.$ values from comparison of observed frequencies with that expected by equal distribution - since the number of each species was equal-all associated with $P>0.05$ ). Of particular interest is that individuals did not initiate interactions with conspecifics more frequently than one would expect by chance in any case.

Of the three species studied, only individuals of $P$. impressus were capable of communication with both of the other species. That is, noninitiating crabs responded appropriately to both diogenid raps and spasmodic shaking raps and initiating individuals of $P$. impressus executed both kinds of acts as well as 'inverse' raps. If $P$. impressus has this relatively large repertoire of acts as a result of selection for efficient interspecific communication, one might expect initiating crabs to execute the acts in different proportions, depending upon the species (or even just the family) of the other crab. The number of executions of each kind of rapping was counted for initiating $P$. impressus, depending upon the species of the noninitiator (Table 5). There were highly significant differences in the raps executed $\left(\chi^{2}=79.31, d f=4, P<0.001\right)$. However, the major deviation from the pattern expected by chance ( $=$ independence of type of rap and species of noninitiator) was in an unexpected direction. More diogenid raps and fewer spasmodic shaking raps were executed when the noninitiator was a $P$. pollicaris.

These results indicate that, at least in the laboratory, crabs (1) readily attempted interspecific exchanges, (2) the outcome of the interactions were not strongly influenced by size or sex, and (3) the crabs did not communicate differently in intra- and interspecific interactions. Moreover, the potential for exchange of shells within members of this guild was clearly realized in some cases, although not in all (P. pollicaris could not effect an exchange with $C$. vittatus).

Species of Shell Involved. Concerning the species of gastropod shell involved in the interactions, three, questions can be asked for each crab species: (1) Were the shells occupied by initiators a distinct subset of the shells occupied by the species in the field? That is, were certain species less preferred as indicated by a higher frequency of attempted exchange? (2) In interactions with exchanges, were the shells vacated by noninitiators a distinct subset of the shells occupied by that (noninitiator's) species in the field? That is, were certain species less preferred as indicated by a higher frequency of being vacated by noninitiators? (3) Were the shells of the noninitiators a distinct subset of the shells occupied by the initiating crab species in the field? Were certain species of gastropod more preferred, as indicated by a higher frequency of attempts to obtain those shells? Since $P$. pollicaris from both sites were used, an average of the shell occupancy frequencies at the two sites was used for the following comparisons.

The shell species of initiating and noninitiating crabs are shown in Table 6. Initiating individuals of C. vittatus were in different shells than the general

Table 6. Distribution of interactions by shell species occupied by interactants. Letters indicate the number of interactions initiated by each crab species $(\mathrm{V}=C$. vittatus, $\mathrm{P}=P$. pollicaris, $\mathrm{I}=P$. impressus $)$

\begin{tabular}{|c|c|c|c|c|c|c|c|c|c|c|}
\hline \multirow{2}{*}{$\begin{array}{l}\text { Shell species } \\
\text { of initiator }\end{array}$} & \multicolumn{10}{|c|}{ Shell species of noninitiator } \\
\hline & B.c. & $M . C$. & F.h. & F.t. & $M . P$. & S.p. & P.d. & $T . h$. & B.s. & T.c. \\
\hline Busycon contrarium & III & & & $\mathrm{PP}$ & $\mathrm{P}$ & $\mathrm{V}$ & I & & I & \\
\hline Melongena corona & $\mathrm{V}$ & & & 1 & & $\mathrm{~V}$ & & & $\mathrm{P}$ & \\
\hline Fasciolaria huntaria & & & & & & I & & & & \\
\hline Fasciolaria tulipa & I & & & & & $\mathrm{V}$ & & & & \\
\hline Murex ponum & I & & & & & $\mathrm{V}$ & V & V & & I \\
\hline Strombus pugilator & & & & V & & & & & II & I \\
\hline Polinices duplicatus & & & & $\mathrm{P}$ & & & & & & \\
\hline Thais haemastoma & & & & & & & $\mathrm{P}$ & & & \\
\hline Busycon spiratum & PP & VVV & & & & $\mathrm{P}$ & PPPP & & VV & \\
\hline Turbo castanea & & & $P$ & $\mathrm{P}$ & & PP & & & & \\
\hline & & & & & & I & & & & \\
\hline
\end{tabular}


population $\left(\chi^{2}=36.15, d f=8, P<0.1\right)$, primarily because crabs in Busycon spiratum were. So few C. vittatus noninitiators vacated their shells $(n=1)$ that nothing can be concluded. The shell species that $C$. vittatus crabs were attempting to obtain were different from the array occupied in the field $\left(\chi^{2}=22.15, d f=8\right.$, $P<0.01$ ), primarily because of an apparent preference for Strombus pugilator (which was not available at Bay Mouth Bar).

Initiating individuals of $P$. pollicaris occupied different shells than the field populations $\left(\chi^{2}=28.7, d f=\right.$ $7, P<0.01$ ), primarily because crabs in $P$. duplicatus shells did not initiate interactions and crabs in $B$. spiratum did. The three shells vacated by noninitiating $P$. pollicaris do not allow any clear statements. The shells that $P$. pollicaris were trying to obtain significantly differed from the shells occupied in the field $\left(\chi^{2}=19.79, d f=7, P<0.01\right)$, primarily because they did not attempt to obtain $T$. castanea and did attempt to obtain both Fasciolaria species. They attempted to obtain Polinices shells most frequently but occupied this species in the field most frequently also.

Initiating individuals of $P$. impressus did not differ in their shell species inhabitation from that expected from the field frequencies $\left(\chi^{2}=6.74, d f=9, P>0.10\right)$, although frequently they were in Busycon contrarium and rarely in olive shells. The nine shells vacated by noninitiating $P$. impressus appeared to be different from the shells not vacated primarily, in that Melongena shells were vacated and Busycon spiratum and $F$. tulipa were not. However, these trends were not significant $\left(\chi^{2}=1.91, d f=8, P>0.10\right)$. The shells that $P$. impressus individuals were attempting to obtain differed significantly from that expected from the field distributions $\left(\chi^{2}=25.01, d f=9, P<0.01\right)$, in that they tried to obtain $F$. tulipa and B. spiratum but not $S$. pugilator or olive shells.

The most interesting result of these patterns of preference by the three species of crabs is that interspecific exchanges can occur which would increase the shell species 'satisfaction' of both interactants. If a $C$. vittatus in a $B$. spiratum exchanges with a $P$. impressus in a $S$. pugilator, both crabs leave a less-preferred shell and get a more-preferred shell. A $P$. pollicaris in a $B$. spiratum and a $P$. impressus in a $P$. duplicatus would also exchange and mutually benefit (or at least both end up in more-preferred shells). Clearly, many other combinations of exchanges would not result in mutual gain with regard to shell species preference.

Length of Interactions. Since preferred shell weights were obtained only for $C$. vittatus, potential gain could only be determined in that species. Gain was calculated as the absolute value of the reduction in the deviation from the preferred shell weight that results from an exchange of shells. Considering all interactions involving $C$. vittatus initiators, there was a significant positive relationship $(r=0.9642, P<0.05)$ between the potential gain for the initiator and the length of the interaction. That is, the more an initiating crab had to gain from an exchange, the longer it would execute raps. It is of special interest that in the interaction in which an initiating $C$. vittatus killed a $P$. impressus (which was $2.5 \mathrm{~mm}$ larger than the $C$. vittatus), the gain of the initiator was by far the largest recorded in this data set.

\section{Discussion}

The pattern of shell exchanges within any assemblage of hermit crabs can be examined at several levels. Behaviorally, we can ask what factors appear to control initiation of exchanges and whether an exchange occurs. Ecologically, we can ask how the pattern of exchange affects resource distribution within the shellutilizing guild. And we can look for evidence of past selection for interspecific communicatory ability. The present data set, although limited, allows comment on each of these levels of analysis.

The species examined in this study overlap in distribution and the use of limiting resources. Under such conditions, I would hypothesize that selection should favor individuals which could gain access to a full array of potentially better resources by communicating with other members of their guild. The species studied did not behave in such a way that this hypothesis is strongly supported. $P$. pollicaris and $P$. impressus can communicate interspecifically, as evidenced by shell exchanges between them. However, since they are taxonomically related, this ability does not necessarily reflect selection for interspecific communication capacity, but could be simply a result of a common ancestry. The apparent ability of individuals of $P$. impressus to respond to the signals of C. vittatus (but not vice versa) is somewhat puzzling since they do not overlap in distribution. This is true both in northern Florida and elsewhere in their ranges (Williams, 1965). One could suggest that other diogenid species (with patterns similar to C. vittatus) overlap and interact with $P$. impressus and this has provided the selective pressure for the 'bilingual' ability of $P$. impressus. Certain Paguristes species, with typical diogenid shell exchange patterns (Hazlett, 1966, 1972) do occur in the subtidal areas to which $P$. impressus seems limited, but none were common in the areas searched. Thus, this must remain as conjecture.

The most striking nonsupport of the communication-niche overlap hypothesis is the lack of communi- 
cation between $P$. pollicaris and $C$. vittatus. The type of signals used do not overlap at all (spasmodic shaking in the pagurid, regular rapping in the diogenid) and, apparently as a result, they do not exchange shells. It could be argued that most individuals of both species do not often encounter a member of the other species. Thus, the selection pressure is low, considering the unpredictability of the communicatory environment which a planktonically dispersed, metamorphosing larva (Lang and Young, 1977) will encounter. $C$. vittatus is always found in the upper intertidal in the summer while $P$. pollicaris ranges from that ecotone to the subtidal (Young, 1978). Offshore winter migrations of $C$. vittatus (Fotheringham, 1975) may bring the species into higher overlap during much of the year. Moreover, C. vittatus populations occur in southern Florida and elsewhere in the Caribbean where $P$. pollicaris is absent (Williams, 1965). However, the species co-occur all along the Gulf Coast, from Texas (Fotheringham, 1976a) to Naples, Florida (Hazlett, personal observation), and from the east coast of florida north to the Carolinas. Even if only a portion of the populations found in those areas overlap in distribution, the opportunities for selection for interspecific communication would seem sufficient.

A complicating factor is the condition of shells utilized by individuals of the two species. P. pollicaris will readily occupy and even prefers (Conover, 1976) shells colonized by live cnidarians, while $C$. vittatus is not found in colonized shells and is reported to avoid them. Wright (1973) has argued that competition between these hermit crabs is reduced by these preferences and $P$. pollicaris is protected from the competitively dominant $C$. vittatus by occupation of hydroid-colonized shells. While this may have an effect, several factors reduce the impact of these differences. In his preference tests, Wright (1973) removed individuals of C. vittatus from shells and presented them with hydroid-covered shells. The low rate of shell entry when the particularly vulnerable abdomen can make contact with hydroids more than in a natural shell entry (from one shell to another) may overestimate the degree of avoidance. Second, both in Texas (Wright, 1973) and in the north Florida sites (Bach and Herrnkind, 1979), less than $30 \%$ of the individuals of $P$. pollicaris occupied shells with cnidarians. That is, the uncolonized shells of $C$. vittatus are acceptable resource items for $P$. pollicaris. Third, both Wright's (1973) field observations and my own (laboratory) indicate that individuals of $C$. vittatus will occupy a colonized shell and the cnidarian is either actively killed by the crab or passively killed by the tendency of C. vittatus to remain either out of water completely or buried in the substrate during the hours of low tide (B.A. Hazlett, in preparation; Wright, 1973). Thus, even the $30 \%$ or fewer shells with hydroids occupied by $P$. pollicaris are available for individuals of C.vittatus.

Differences in geographic distribution, ecotone preferences, and shell preferences may explain the failure of this species pair to support the communication-niche overlap hypothesis. This 'explanation' is, however, just as unsatisfying from an experimentalist's viewpoint as falling back on phylogentic inertia as a reason.

The patterns of shell exchanges initiated and effected indicate a very significant effect of shell species on the behavior patterns of the individuals involved. For all three species, it appears that frequently crabs initiated exchanges when they occupied shells of less-desired species and were attempting to obtain shells of more-desired species. Noninitiating crabs tended not to allow an exchange if it would result in an overall decrease in the desirability of the shell species occupied, and allowed an exchange if it would result in an overall increase in the desirability of the shell eventually occupied. This interspecific effect parallels the intraspecific results of shell exchange seen in the European species Pagurus bernhardus (Hazlett, 1978) where shell size fit was the factor maximized by both interactants.

At the ecologic level, these results imply a compounding of the effects of interspecific interactions, at least for $P$. pollicaris and $P$. impressus. On the one hand, the presence and shell use of crabs of one species may decrease the fitness of individuals of a second species, i.e., competitive effects as documented by Bach et al. (1976) and Fotheringham (1976a). At the same time, the fitness of individuals of both species may be increased by an exchange, both by obtaining shells of a more appropriate size and/or species. This might be of only passing interest if all sizes and species of shells of potential utility were available in a given locale. However, it is not hard to imagine shells becoming available in one part of the environment (due to gastropod death) and the availability of those shells to crabs limited to a different part of the environment being dependent upon transport by crabs of a different species (such as $P$. pollicaris, which ranges widely in its habitats), as suggested by Spight (1977). The second crab species could then profit by the resource supply activities of the first. Further research is clearly needed, but the potential for simultaneous positive and negative interspecific effects with regards to the same resource category is clearly present.

Acknowledgements. Thanks are given to the Florida State University Marine Laboratory and the Psychobiology Program of Florida 
State University for support of this research. Thanks are also given to Peter Abrams, Catherine Bach, and John Vandermeer for their comments on the manuscript.

\section{References}

Bach, C.E., Hazlett, B.A., Rittschof, D.: Effects of interspecific competition on fitness of the hermit crab Clibanarius tricolor. Ecology 57, 579-586 (1976)

Caine, E.A.: Feeding and masticatory structures of selected anomure (Crustacea). J. Exp. Mar. Biol. Ecol. 18, 277-301 (1975)

Cody, M.L.: Competition and the structure of bird communities. Princeton: Princeton University 1974

Colwell, R.K., Futuyma, D.J.: On the measurement of niche breadth and overlap. Ecology 52, 567-576 (1971)

Conover, M.R.: The influence of some symbionts on the shellselection behaviour of the hermit crabs, Pagurus pollicarus and Pagurus longicarpus. Anim. Behav. 24, 191-194 (1976)

Drapkin, E.I. : Effect of Rapana bezear Linne (Molluca, Muritidae) on the Black Sea fauna. Dokl. Akad. Nauk SSSR 151, 700-703 (1963)

Fotheringham, N.: Structure of seasonal migrations of the littoral hermit crab Clibanarius vittatus (Bosc). J. Exp. Mar. Biol. Ecol. 18, 47-53 (1975)

Fotheringham, N.: Effects of shell stress on the growth of hermit crabs. J. Exp. Mar. Biol. Ecol. 23, 299-305 (1976a)

Fotheringham, N.: Population consequences of shell utilization by hermit crabs. Ecology 57, 570-578 (1976b)

Hazlett, B.A.: Social behavior of the Paguridae and Diogenidae of Curacao. Stud. Fauna Curacao 23, 1-143 (1966)

Hazlett, B.A.: Tactile stimuli in the social behavior of Pagurus bernhardus (Decapoda, Paguridae). Behaviour 36, 20-48 (1970)

Hazlett, B.A.: Shell fighting and sexual behavior in the hermit crab genera Paguristes and Calcinus, with comments on $\mathrm{Pa}$ gurus. Bull. Mar. Sci. 22, 806-823 (1972)
Hazlett, B.A.: Shell exchanges in hermit crabs: Aggression, negotiation or both? Anim. Behav, 26, 1278-1279 (1978)

Kellogg, C.W.: Gastropod shells: A potentially limiting resource for hermit crabs. J. Exp. Mar. Biol. Ecol. 22, 101-111 (1976)

Lang, W.H., Young, A.M.: The larval development of Clibanarius vittatus (Bosc) (Crustacea: Decapoda; Diogenidae) reared in the laboratory. Biol. Bull. 152, 84-104 (1977)

Markham, J.C.: Notes on growth-pattern and shell-utilization of the hermit crab Pagurus bernhardus (L). Ophelia 5, 189-205 (1968)

Murray, B.D., Jr.: A critique of interspecific territoriality and character convergence. Condor 78, 518-525 (1974)

Orians, G.H., Willson, M.F.: Interspecific territories of birds. Ecology 45, 736-745 (1964)

Provenzano, A.J., Jr.: Notes on Bermuda hermit crabs (Crustacea; Anomura). Bull. Mar. Sci. 10, 117-124 (1960)

Reese, E.S.: Shell use: An adaptation for emigration from the sea by the coconut crab. Science 161, 385-386 (1968)

Reese, E.S. : Behavioral adaptations of intertidal hermit crabs. Am. Zool. 9, 343-355 (1969)

Rice, J.: Ecological relationships of two interspecifically territorial vireos. Ecology 59, 526-538 (1978)

Spight, T.M.: Availability and use of shells by intertidal hermit crabs. Biol. Bull. 152, 120-133 (1977)

Vance, R.R.: Competition and mechanism of coexistence in three sympatric species of intertidal hermit crabs. Ecology 53, 1062-1074 (1972)

Williams, A.B. : Marine decapod crustaceans of the Carolinas. Fish. Bull. 65, 1-298 (1965)

Wilson, E.O.: The insect societies. Cambridge: Belknap 1971

Wright, H.O.: Effect of commensal hydroids on hermit crab competition in the littoral zone of Texas. Nature 241, 139-140 (1973)

Young, A.M.: Desiccation tolerances for three hermit crab species Clibanarius vittatus (Bosc), Pagurus pollicaris Say and P. longicarpus Say (Decapoda, Anomura) in the North Inlet Estuary, South Carolina, USA Est. Coast Mar. Sci. 6, 117-122 (1978) 